\title{
Genomic Regions Associated with Virulence in Pyrenophora teres f. teres Identified by Genome-Wide Association Analysis and Biparental Mapping
}

\author{
Anke Martin, ${ }^{1, \dagger}$ Paula Moolhuijzen, ${ }^{2}$ Yongfu Tao, ${ }^{3}$ Judy McIlroy, ${ }^{3}$ Simon R. Ellwood, ${ }^{2}$ Ryan A. Fowler, ${ }^{3}$ Greg J. Platz, ${ }^{3}$ \\ Andrzej Kilian, ${ }^{4}$ and Lisle Snyman ${ }^{3}$ \\ ${ }^{1}$ Centre for Crop Health, University of Southern Queensland, Toowoomba, Queensland 4370, Australia \\ ${ }^{2}$ Centre for Crop \& Disease Management, Department of Environment and Agriculture, Curtin University, Bentley, Western Australia \\ 6102, Australia \\ ${ }^{3}$ Hermitage Research Facility, Department of Agriculture \& Fisheries, Warwick, Queensland 4370, Australia \\ ${ }^{4}$ Diversity Arrays Technology, Bruce, Australian Capital Territory 2617, Australia \\ Accepted for publication 16 December 2019.
}

\begin{abstract}
Net form net blotch (NFNB), caused by the fungal pathogen Pyrenophora teres f. teres, is an important foliar disease present in all barley-producing regions of the world. This fungus is a hemibiotrophic and heterothallic ascomycete, where sexual recombination can lead to changes in disease expression in the host. Knowledge of the genetic architecture and genes involved in virulence is vital to increase the durability of NFNB resistance in barley cultivars. We used a genome-wide association mapping approach to characterize $P$. teres $\mathrm{f}$. teres genomic regions associated with virulence in Australian barley cultivars. One hundred eighty-eight $P$. teres $\mathrm{f}$. teres isolates collected across five Australian states were genotyped using Diversity Arrays Technology sequence markers and phenotyped across 20 different barley genotypes. Association mapping identified 14 different genomic regions associated with virulence, with the majority located on P. teres f. teres
\end{abstract}

ABSTRACT

chromosomes 3 and 5 and one each present on chromosomes 1, 6, and 9 . Four of the regions identified were confirmed by quantitative trait loci (QTL) mapping. The QTL regions are discussed in the context of their genomic architecture together with examination of their gene contents, which identified 20 predicted effectors. The number of QTL shown in this study at the population level clearly illustrates a complex genetic basis of $P$. teres f. teres virulence compared with pure necrotrophs, such as the wheat pathogens Parastagonospora nodorum and Parastagonospora tritici-repentis.

Keywords: candidate genes, disease control and pest management, genetics and resistance, genome-wide association mapping, Pyrenophora teres f. teres, QTL analysis, virulence
Net blotch caused by the fungal pathogen, Pyrenophora teres, was first recorded in Australia as an important foliar disease of barley (Hordeum vulgare) in the 1960s. In other countries, such as the United States, yield losses owing to this disease were recorded as early as 1922 (McLean et al. 2009; Shipton 1966). Net blotch is found in all barley-producing regions of the world (Liu et al. 2011). In 1971, net blotch was classified as two forms, namely those having net-like symptoms ( $P$. teres $\mathrm{f}$. teres) and others having spot-like symptoms (P. teres f. maculata) (SmedegårdPetersen 1971). Smedegård-Petersen (1971) successfully produced progeny from crosses between $P$. teres $\mathrm{f}$. teres and $P$. teres $\mathrm{f}$. maculata, which confirmed the belief that the two pathogens are of different forms rather than two different species. However, phylogenetic studies indicate that they are discrete populations, and natural field hybrids seem to be rare events (Ellwood et al. 2012; Poudel et al. 2017, 2019a). P. teres is a heterothallic haploid ascomycete, requiring two opposite mating genotypes for sexual reproduction (Rau et al. 2007). The fruiting bodies are pseudothecia, which are produced on barley straw during sexual reproduction. They are dark brown globoid bodies with spiky

†Corresponding author: A. Martin; anke.martin@usq.edu.au

Funding: Funding was provided by Grains Research and Development Corporation grant DAQ000187.

*The $e$-Xtra logo stands for "electronic extra" and indicates that seven supplementary figures and five supplementary tables are published online.

The author(s) declare no conflict of interest.

(C) 2020 The American Phytopathological Society setae. The pseudothecia contain club-shaped asci with eight ascospores (Liu et al. 2011). Under wet conditions, ascospores can be distributed by rain splash or discharged into still air (Jordan 1981). Mature pseudothecia can cause primary infection of barley grown a number of years after an infected barley crop was produced (Jordan 1981; Liu et al. 2011; McLean et al. 2009; Piening 1961). Asexually produced conidia are a secondary source of inoculum, and these are produced under favorable conditions throughout the growing season (Lai et al. 2007).

Sexual recombination can lead to changes in both disease expression in the host and also, fungicide sensitivity in the pathogen (Campbell et al. 1999; Jalli 2011). Changes in virulence can be devastating to the barley industry, especially if a limited number of barley cultivars with common resistances are grown. In a 2017 study, the composition of isolate groups determined by hierarchical clustering of barley genotypes and $P$. teres f. teres isolate phenotypes was found to be different between eastern and western Australia, with all isolate groups detected in southern Australia (Fowler et al. 2017). This suggested that P. teres f. teres pathotypes had evolved regionally depending on the barley cultivars prevalent in a certain region. The authors identified four distinct isolate groups by phenotyping $P$. teres $\mathrm{f}$. teres isolates across 31 different barley genotypes (Fowler et al. 2017). These isolate groups harbored differential virulence to the four barley genotypes: Maritime, Prior, Skiff, and Tallon. Isolates with virulence to any of these four genotypes made up $97 \%$ of the total 123 isolates tested. Knowledge of the genetic structure and range of genes involved in virulence is vital to researchers and breeders to increase the durability of $P$. teres f. teres resistance in barley cultivars.

Different approaches can be used to characterize genomic regions associated with virulence; these include association mapping and 
quantitative trait loci (QTL) analysis using biparental populations. The effective use of association mapping in fungi has been confirmed in fungal studies (Broberg et al. 2018; Castiblanco et al. 2017; Gao et al. 2016; Hartmann et al. 2017; Korinsak et al. 2019; Talas et al. 2016). Association mapping requires high-throughput genotyping and sequencing methods to provide large numbers of markers. One such method, Diversity Arrays Technology sequence (DArTseq), has been developed for a number of fungal pathogens, including $P$. teres (Poudel et al. 2019b; Sharma et al. 2014; Syme et al. 2018; Wittenberg et al. 2009). DArTseq involves a combination of genomic complexity reduction methods and next generation sequencing, where the markers detect single-nucleotide polymorphisms (SNPs) and the presence/absence of fragments (Courtois et al. 2013; Cruz et al. 2013; Kilian et al. 2012; Raman et al. 2014).

The first report on the identification of genetic markers associated with virulence in a $P$. teres $\mathrm{f}$. teres/P. teres $\mathrm{f}$. teres population used a cross between isolates 0-1 and 15A (Weiland et al. 1999). Random amplified polymorphic DNA markers were used to identify five markers that were associated with the virulence phenotype. Lai et al. (2007) used the same population to identify a gene conferring avirulence to cultivars Tifang and Canadian Lake Shores and two avirulence genes on Prato. Six amplified fragment length polymorphism (AFLP) markers located close to an avirulence gene to cultivar Heartland were identified by Beattie et al. (2007), who used a bulked segregant analysis approach using 67 progeny from a P. teres f.teres/P. teres f. teres cross between isolates WRS 1906 and WRS 1607. Shjerve et al. (2014) used 118 progeny from a cross between isolates 15A and 6A to identify two major QTL associated with virulence on Kombar and Rika. Three progeny isolates harboring different single-virulence genes were screened across a Kombar/Rika barley population, and the susceptibility induced by each of these isolates was mapped to the same region on chromosome $6 \mathrm{H}$. This study demonstrated that isolate-host interactions can in part be explained by pathogen-produced necrotrophic effectors that interact with dominant susceptibility genes of barley, resulting in necrotrophic effector-triggered susceptibility. In 2017, avirulence/ virulence gene regions were mapped in 109 progeny of a $P$. teres $\mathrm{f}$. teres/ $P$. teres $\mathrm{f}$. teres cross using isolate BB25 from Denmark and isolate FGOH04Ptt-21 from the United States as parents (Koladia et al. 2017). Nine unique QTL, of which three had major effects, were identified on eight linkage groups.

To gain a better understanding of the number of virulence genes present in Australian P. teres f. teres isolates and to identify genomic regions associated with virulence, we have used a genome-wide association study (GWAS) mapping approach with DArTseq markers genotyped on 188 P. teres $\mathrm{f}$. teres isolates collected across five different Australian states. We confirmed the major regions identified through GWAS by QTL mapping using two different $P$. teres $\mathrm{f}$. teres/P. teres $\mathrm{f}$. teres populations. To provide gene candidates for further functional studies, QTL regions were explored for predicted effector-like proteins (Syme et al. 2018) and secreted proteins known to be expressed in planta during net blotch disease of barley (Ismail and Able 2016, 2017). Knowledge of the virulence genes present in the population will provide barley breeding programs with valuable information for future breeding of $P$. teres f. teres-resistant barley cultivars.

\section{MATERIALS AND METHODS}

P. teres f. teres isolates. Two different types of populations were used to investigate the genetic basis underlying virulence in P. teres f.teres. A panel of isolates capturing the Australian diversity was used in genome-wide association analysis, and biparental populations were used in QTL analysis. The panel consisted of 188 $P$. teres f. teres isolates, including 61 collected from Queensland, 30 collected from New South Wales, 49 collected from South Australia, 11 collected from Victoria, and 37 collected from Western Australia (Supplementary Table S1). Single conidial cultures were obtained as indicated in Fowler et al. (2017).
The two biparental populations were produced similar to the method described in Smedegård-Petersen (1971). Isolate NB029 was separately crossed with HRS09122 and NB085. NB029 was originally sampled in Western Australia and is virulent on barley cultivar Beecher and avirulent on Skiff and Prior, whereas HRS09122 was sampled in New South Wales and is virulent on Skiff and avirulent on Beecher and Prior. Isolate NB085 originated from Queensland and is virulent on Prior and avirulent on Beecher and Skiff. Plates for crossings were prepared by placing five to six 50-mm-long autoclaved barley straw pieces on Sach's agar (Hebert 1971 ) before the agar had set. Isolates were grown on potato dextrose agar (PDA) to obtain enough mycelial growth for the crossing plates. An approximately $25-\mathrm{mm}^{2}$ mycelial plug from each of the two isolates was taken from the PDA plates and placed on opposite sides of the barley straw. Plates were placed into plastic bags to prevent desiccation of the media and incubated at $15^{\circ} \mathrm{C}$ with a 12-h light/12-h dark photoperiod. Plates were checked each week for the formation of mature pseudothecia. After mature pseudothecia were observed (i.e., pseudothecia were forming a short cylindrical beak or neck), $1 \%$ water agar plates were placed on top of the crossing plate with the agar facing the pseudothecia. Plates were sealed with PARAFILM M (Merck Pty Ltd.) and returned to the incubator. Plates were checked each day for ascospores. Ascospores were obtained within 3 and 2 months of setting up the NB029/HRS09122 and NB029/NB085 populations, respectively. Ascospores that had been ejected onto the water agar were removed with a sealed glass needle, and single ascospores were transferred onto PDA plates. These were incubated at $22^{\circ} \mathrm{C}$ until enough fungal mycelium had been produced for DNA extraction. All ascospores were collected, and DArTseq markers were used to identify identical ascospores. One ascospore from each identical pair was removed from further analyses to avoid clones from the same ascus. Thus, of the 107 ascospores obtained for the NB029/HRS09122 population, 78 were unique and used in subsequent analyses. Similarly, 72 of the 89 ascospores collected for the NB029/NB085 population were used in further analyses.

Phenotypic evaluation of association mapping isolates. Production of conidia for phenotypic assessment was conducted as described in Fowler et al. (2017). The 188 isolates used in association mapping were phenotyped at the seedling stage across 20 different barley genotypes (Algerian, Beecher, Buloke, CIho 5791, CIho 11458, Commander, Corvette, Fleet, Gilbert, Harbin, Harrington, Herta, Hindmarsh, Kombar, Maritime, Prior, Skiff, Tallon, Vlamingh, and Yerong). These barley genotypes were chosen because they exhibited different resistance profiles (Fowler et al. 2017). The experimental design was similar to that used in Fowler et al. (2017) using a split-plot design with two replicates and randomized barley genotypes. Five seeds of each differential line were sown into a $10-\mathrm{cm}$ pot at three evenly spaced positions around the circumference of the pot. Seedlings were grown in pots containing Searles premium potting mix and fertilized twice a week after emergence with Grow Force Flowfeed soluble fertilizer at 1.5 $\mathrm{g} /$ liter applied via a watering can. Seedlings were top watered until inoculation. Plants were grown and maintained in a growth room at $24 / 14^{\circ} \mathrm{C}$ day/night temperature and with a 12-h light/12-h dark photoperiod as indicated in Fowler et al. (2017). Plants were inoculated 13 days after potting when most genotypes were at growth stage 12 (Zadoks et al. 1974). Inoculations were conducted as indicated in Fowler et al. (2017) using a KC-625CG gravity feed spray gun. Postinoculation, plants were immediately transferred to a dew chamber and maintained at $99 \%$ relative humidity and $19^{\circ} \mathrm{C}$ under a 14-h dark and 10-h light photoperiod. Pots were then returned to the growth room and bottom watered until development of disease infection.

Phenotypic evaluation of $P$. teres f. teres populations. Four different barley genotypes (Beecher, Skiff, Prior, and Kombar) were used to examine virulence of individuals of the NB029/HRS09122 and NB029/NB085 cross. Variety Kombar was 
used as the susceptible control. Four seeds each of four different genotypes were sown into one 15 -cm-diameter pot, with clusters of seeds of each genotype evenly spaced around the circumference of the pot. Two replicates were grown for each isolate. Pots were placed in a glass house for 14 days prior to inoculation.

Conidia were produced by placing five plugs of a mycelial culture on the margins of sterilized sorghum or maize leaf segments on $1 \%$ water agar medium (Lightfoot and Able 2010). Plates were incubated in the laboratory at approximately $22^{\circ} \mathrm{C}$ under natural daylight conditions for 6 days. They were then incubated at $15^{\circ} \mathrm{C}$ for another 4 days with a 12-h light/12-h dark photoperiod. To remove conidia, distilled water containing two drops of Tween 20 per $100 \mathrm{ml}$ of water was added to the fungal plate, and the conidia were dislodged with a fine paintbrush into a beaker. Conidia were counted using a hemocytometer, and the conidial suspension was adjusted to 10,000 conidia per milliliter. This inoculum suspension was applied at $2.5 \mathrm{ml}$ per pot using a Preval sprayer (SEDL Agencies). Pots were randomly placed in an Aralab Dew Chamber (Bioline Australia) at $19^{\circ} \mathrm{C}$ for $24 \mathrm{~h}$ in the dark. Pots were then transferred into a glass house with natural day/night light.

Disease assessment. The Tekauz (1985) 1 to 10 scale was used to rate the infection response of the second leaf of at least three plants per genotype 9 days after inoculation. Disease ratings did not differ by more than two units across replications.

DArTseq analysis. Single-spore isolates were grown on PDA at $22^{\circ} \mathrm{C}$ for about 1 week until enough mycelial growth was available for DNA extraction. The DNA of the isolates and ascospores was extracted with a Wizard Genomic DNA Purification kit following the protocol of the supplier (Promega Corporation). DNA of the 188 isolates for use in association mapping, 107 progeny of the NB029/HRS09122, and 89 progeny of the NB029/ NB085 population plus the parents of the populations were sent to Diversity Arrays Technology Pty Ltd. (https://www.diversityarrays. $\mathrm{com} /$ ) for DArTseq analysis. DNA samples were processed in digestion/ligation reactions principally as described in Kilian et al. (2012) but replacing a single PstI-compatible adaptor with two different adaptors corresponding to two different restriction overhangs. The PstI-compatible adapter was designed to include the Illumina flow cell attachment sequence, sequencing primer sequence, and "staggered" varying-length barcode regions, similar to the sequence reported by Elshire et al. (2011). Reverse adapters contained the flow cell attachment region and MseI-compatible overhang sequence. Only "mixed fragments" (PstI-MseI) were effectively amplified in 30 rounds of PCR using the following reaction conditions: $94^{\circ} \mathrm{C}$ for $1 \mathrm{~min} ; 30$ cycles of $94^{\circ} \mathrm{C}$ for $20 \mathrm{~s}, 58^{\circ} \mathrm{C}$ for $30 \mathrm{~s}$, and $72^{\circ} \mathrm{C}$ for $45 \mathrm{~s}$; and a final step of $72^{\circ} \mathrm{C}$ for $7 \mathrm{~min}$. After amplification, equimolar amounts of the products from each sample of the 96-well microtiter plate were bulked and applied to a c-Bot (Illumina) bridge PCR followed by sequencing on the Illumina Hiseq2500 platform. The sequencing (single read) was run for 77 cycles. Sequences generated from each lane were processed using proprietary Diversity Arrays Technology analytical pipelines. In the primary pipeline, the fastq files were first processed to filter away poor-quality sequences, applying more stringent selection criteria to the barcode region compared with the rest of the sequence so that the assignments of the sequences to specific samples carried in the "barcode split" step were very reliable. Approximately 2,000,000 ( $\pm 7 \%)$ sequences per barcode or sample were used in marker calling. Identical sequences were collapsed into "fastqcall files." These files were used in the secondary pipeline for Diversity Arrays Technology Pty Ltd.'s proprietary SNP and SilicoDArT (presence/absence of restriction fragments in representation) calling algorithms (DArTsoft14).

Only markers of known chromosomal location and minor allele frequency $(\mathrm{MAF})>0.01$ were used in the population structure and GWAS analyses. Individual SNP markers with $>50 \%$ missing data were removed from further analysis.

Population structure analysis and linkage disequilibrium analysis. STRUCTURE version 2.3.4 (Pritchard et al. 2000) was used to infer the genetic structure and the number of clusters $(K)$ in the dataset. Ten independent runs were performed for each value of $K$ ( $K$ varying from one to six). The default settings of the program were used (i.e., admixture ancestry model, uncorrelated allele frequencies between populations, and the degree of admixture $\alpha$ inferred from the data) (Falush et al. 2007, Pritchard and Wen 2003). Each run was set to a burn-in period of 10,000 iterations followed by 100,000 Monte Carlo Markov Chain iterations. The most likely number of clusters was chosen by computing Evanno's $\Delta K$ (Evanno et al. 2005) across multiple values of $K$ through the web-based program STRUCTURE HARVESTER v.0.6.94 (Earl and Vonholdt 2012). CLUMPP version 1.1.1 (Jakobsson and Rosenberg 2007) was used to permute 1 output from the 10 independent cluster outputs produced by STRUCTURE, and the graph was constructed in Microsoft Excel 2013. Pairwise linkage disequilibrium (LD; $r^{2}$ ) was calculated using TASSEL version 5.2.58 with MAF $>0.01$. The LD decay graph was drawn by fitting a smooth spline of average $r^{2}$ over physical distance in $\mathrm{R}$ version 3.3.1.

Genome-wide association analysis. GWAS analysis was performed using the mixed linear model in TASSEL version 5.2.59 (Bradbury et al. 2007). $Q$ matrix and $K$ matrix were calculated using built-in functions in TASSEL version 5.2.59 to control population structure and genetic relatedness, respectively. Thresholds for defining significant associations were set using the Bonferroni correction. This $P$ value was used to estimate the significant logarithm of the odds (LOD) score by using the equation LOD = $\times \log 10(P)$. Manhattan plots were drawn using the Memory-efficient, Visualization-enhanced, and Parallel-accelerated Tool in $\mathrm{R}$ version 3.6.1 (https://github.com/xiaolei-lab/rMVP).

QTL analysis. Genetic linkage maps were produced for populations NB029/HRS09122 and NB029/NB085. MapManager QTXb20 (Manly et al. 2001) was used to partition DArTseq markers into linkage groups, and RECORD (Van Os et al. 2005) was used to order markers within linkage groups. The Kosambi function was used to calculate map distances. Map figures were produced with MapChart version 2.1 (Voorrips 2002). Composite interval mapping was conducted using Windows QTL Cartographer version 2.5 (Wang et al. 2007). A permutation test run 1,000 times at a significance level of 0.05 was used to determine the LOD threshold.

$P$. teres f. teres net form net blotch QTL gene analysis. The P. teres f. teres isolate W1-1 genome (Syme et al. 2018) was used as the reference throughout this analysis. The genomic positions of the markers identified in the GWAS analysis were located in the W1-1 reference genome. Candidate effector genes were searched for $20 \mathrm{~kb}$ (based on the locus disequilibrium calculation) either side of a marker (Supplementary Table S2). A flanking region of $40 \mathrm{~kb}$ was estimated to be the same QTL/GWAS region.

W1-1-predicted gene annotation that overlapped QTL regions was then identified using bedtools intersect v2.26.0 (Quinlan 2014), and potential biosynthetic gene clusters (BGC) were identified using antiSmash fungal version 5.0.0 (Blin et al. 2019) with options for KnownClusterBlast, ActiveSiteFinder, ClusterBlast, Cluster Pfam analysis, and SubClusterBlast. In addition, secreted proteins during net blotch disease of barley (Ismail and Able 2016, 2017) were retrieved for predicted effector gene support.

Other available $P$. teres $\mathrm{f}$. teres isolates (NB029, NB073, NB085, HRS09122, and HRS09139) (Syme et al. 2018) that show specific virulence on Beecher, Shepherd, Prior, Skiff, and Fleet barley cultivars, respectively, were selected to identify genomic regions of presence/absence for the 14 QTL regions. High-quality PacBio genome assembly sequences for $P$. teres f. teres isolates NB029, NB085, NB073, HRS09122, and HRS09139 were aligned to W1-1 using MUMmer NUCmer version 3.1 (Delcher et al. 2003), and W1-1 genome coordinates were used to identify regions of presence and absence for each isolate. All W1-1 genes, isolate alignments, and $\mathrm{BGC}$ regions were then visualized with the Integrated Genome Viewer version 2.5.0 (Thorvaldsdottir et al. 2013). The genomes 
for NB029 (WJSO00000000), NB073 (WJSN00000000), NB085 (WJSM00000000), HRS09122 (WJSL00000000), and HRS09139 (WJSK00000000) are available under NCBI BioProject PRJNA577527, and W1-1 (OCTH00000000) is available under PRJEB18107.

\section{RESULTS}

DArTseq genotyping and LD decay. Genotyping by DArTseq analysis of the $188 P$. teres $\mathrm{f}$. teres isolates used in population structure and association mapping analysis provided 14,286 SilicoDArT (dominant markers) and 6,662 SNP markers. Individual SNP markers with $>50 \%$ missing data were removed from further analysis. This resulted in 2,277 SilicoDArT and 1,113 SNP markers or 3,390 markers in total used in the analyses. The distribution and density of markers present on each of the 12 P. teres f. teres chromosomes are indicated in Supplementary Figure S1. Rapid LD decay was observed in this population to within half of the maximum at approximately $20 \mathrm{~kb}$ and to background level at $125 \mathrm{~kb}$ (Fig. 1).

Population structure. Model-based structuring analysis of the P. teres f. teres isolates using the 3,390 markers in STRUCTURE indicated that the most likely number of clusters was $K=2$ (Fig. 2 and Supplementary Table S3) based on the rate of variation in likelihood values between successive $K$ values (Evanno et al. 2005). Isolates were assigned into the specific groups based on the highest percentage of membership with isolates having $<70 \%$ similarity considered to be of mixed origin; 80 and 89 isolates clustered within groups 1 and 2, respectively, and 19 isolates were considered to be of mixed origin (Fig. 3A and Supplementary Table S4). Of the isolates used in the biparental QTL mapping populations, HRS09122 was placed in group 1, and isolates NB029 and NB085 were placed in group 2. No geographical patterns were observed within the groups, with isolates from the five Australian states occurring in similar numbers within both groups.

Phenotypic assessments of $P$. teres f. teres isolates. Phenotyping for the GWAS analysis involved the assessment of the $P$. teres $\mathrm{f}$. teres isolates across 20 different genotypes (Supplementary Fig. S2 and Supplementary Table S1). Isolates HRS15059b, NB270, and HRS18021a had the highest average infection response $(\geq 7)$ across all cultivars. A high proportion of

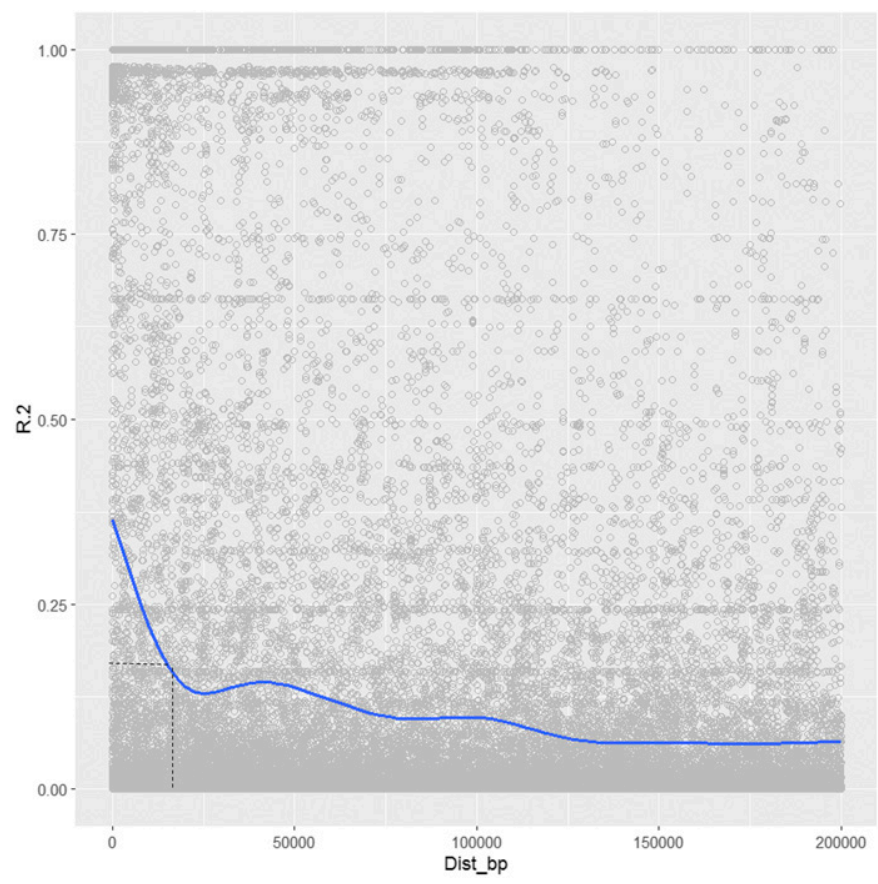

Fig. 1. Linkage disequilibrium decay based on 3,390 Diversity Arrays Technology marker positions located on 12 chromosomes of Pyrenophora teres f. teres. isolates was virulent on barley genotypes Commander, Gilbert, and Harrington, with average infection responses $>7$. Genotype CIho 5791 was resistant to all 188 isolates with an average infection response of 1.2, and CIho 11458 and Vlamingh were resistant to most of the isolates tested with an average infection response of 2.8. For some barley genotypes, a clear difference in infection responses was observed between the clusters determined by STRUCTURE analysis (i.e., isolates virulent on Beecher, Maritime, and Prior clustered mainly in group 1, and isolates virulent on Skiff and Herta clustered mainly in group 2) (Fig. 3B).

Infection responses of the 78 ascospores of the NB029/ HRS09122 population ranged from avirulent to virulent on both Beecher and Skiff (Fig. 4), with average infection responses of 4.603 (standard error $=0.227)$ and $6.026($ standard error $=0.278)$ for Beecher and Skiff, respectively. Eight individuals were virulent (infection responses $\geq 7$ ) on both Beecher and Skiff. The 72 ascospores of the NB029/NB085 population screened across barley genotypes Beecher and Prior had infection responses ranging from avirulent scores of 1 to virulent scores of 10 , with most of the isolates having intermediate or virulent infection responses on Prior (Fig. 5). Average infection responses of 6.127 (standard error $=$ 0.321 ) and 7.556 (standard error $=0.269$ ) were observed for Beecher and Prior, respectively. Twenty-five individuals of the NB029/NB085 population were virulent (infection responses $\geq 7$ ) on both Beecher and Prior.

Genome-wide association analysis of virulence genes. Genome-wide association analysis was conducted using the infection response of $188 P$. teres $\mathrm{f}$. teres isolates on 20 different barley genotypes to identify genomic regions associated with virulence. For a marker to be significantly associated with a trait, a Bonferroni significance threshold of $>4.8$ LOD $(P=1.475 \mathrm{E}-5)$ was used. Thirty-nine significant marker-trait associations were identified for 13 of the 20 barley genotypes (Fig. 6 and Table 1). Markers associated with $P$. teres f. teres infections were further clustered into QTL using a window of $20 \mathrm{~kb}$ based on an approximate LD decay to half the maximum, resulting in 14 different QTL regions. Five different QTL were identified for Beecher, with three of these located on chromosome 3 (QTL3, QTL4, and QTL7) and one each on chromosomes 1 (QTL1) and 9 (QTL14) with the proportion of phenotypic variances explained between 10.2 and 23.6\%. Two of the QTL on chromosome 3 (QTL3 and QTL4) were also observed with Maritime and explained between 12.7 and $18.7 \%$ of the phenotypic variance. Four more QTL were identified at different positions on chromosome 3 (QTL2, QTL5, QTL6, and QTL8); two of these were present with the genotypes Herta and Skiff. Four different QTL locations were identified on chromosome 5; two of these were identified with genotypes Fleet and Yerong (QTL9 and QTL10) and explained between 17.6 and $23.0 \%$ of the phenotypic

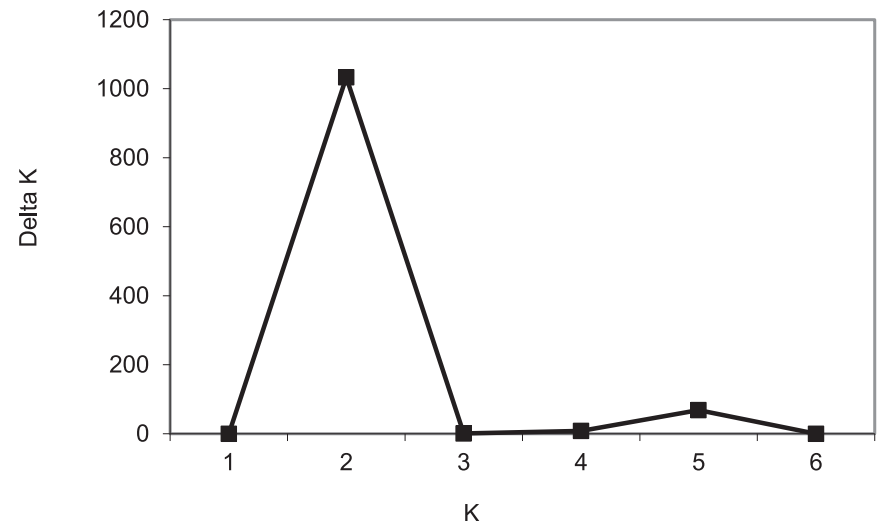

Fig. 2. STRUCTURE analysis of 188 Pyrenophora teres f. teres isolates indicating estimated $\Delta K$ values for 10 independent runs from $K 1$ to $K 6$. 
variance. Harbin and Prior virulence rates were also associated with chromosome 5 (QTL11 and QTL12). AQTL on chromosomes 6 (QTL13) explaining $10.9 \%$ of the phenotypic variance was associated with the Tallon virulence. The locations of the 14 association mapping QTL on the W1-1 chromosomes are summarized in Supplementary Figure S3.

Linkage mapping and biparental QTL analysis. In total, $>1,800$ SilicoDArT and SNP markers were obtained for the biparental $P$. teres $\mathrm{f}$. teres populations through DArTseq analysis. Of these, 733 and 524 high-quality markers for populations NB029/ HRS09122 and NB029/NB085, respectively, were polymorphic, and they were allocated to linkage groups. The genetic map of population NB029/HRS09122 consisted of 12 linkage groups ranging in size from 89.49 to $290.85 \mathrm{cM}$, with a total map distance of $1,998 \mathrm{cM}$ (Supplementary Fig. S4). Chromosomes are numbered relative to the reference genome $P$. teres $\mathrm{f}$. teres W1-1 (Syme et al. 2018). Population NB029/NB085 also had a genetic map consisting of 12 linkage groups ranging in size from 49.29 to $227.39 \mathrm{cM}$, and the total map distance was 1,548 cM (Supplementary Fig. S5). The average distances between markers were 2.73 and $2.95 \mathrm{cM}$ for the NB029/HRS09122 and NB029/NB085 maps, respectively; 348 and 255 markers were nonredundant in the NB029/HRS09122 and NB029/NB085 populations, respectively, and they were used in the QTL analysis. Based on the size of the P. teres f.teres W1-1 genome estimated at $49 \mathrm{Mb}$ (Syme et al. 2018), the physical to genetic distance ratios for the NB029/HRS09122 and NB029/NB085 populations are approximately 25 and $32 \mathrm{~kb} / \mathrm{cM}$, respectively. Most of the markers in common between the populations were in the same order on both maps (Supplementary Fig. S6).

A LOD value threshold of three was used to identify significant QTL after performing 1,000 permutations on each of the datasets. Four significant QTL were identified in each population. In the NB029/HRS09122 population, a major virulence QTL on chromosome 3 was identified against barley cultivar Skiff, explaining $24 \%$ of the phenotypic variation $(\mathrm{LOD}=6.6$ ) (Table 2$)$. This QTL was in the same position as QTL2 identified with the Skiff and

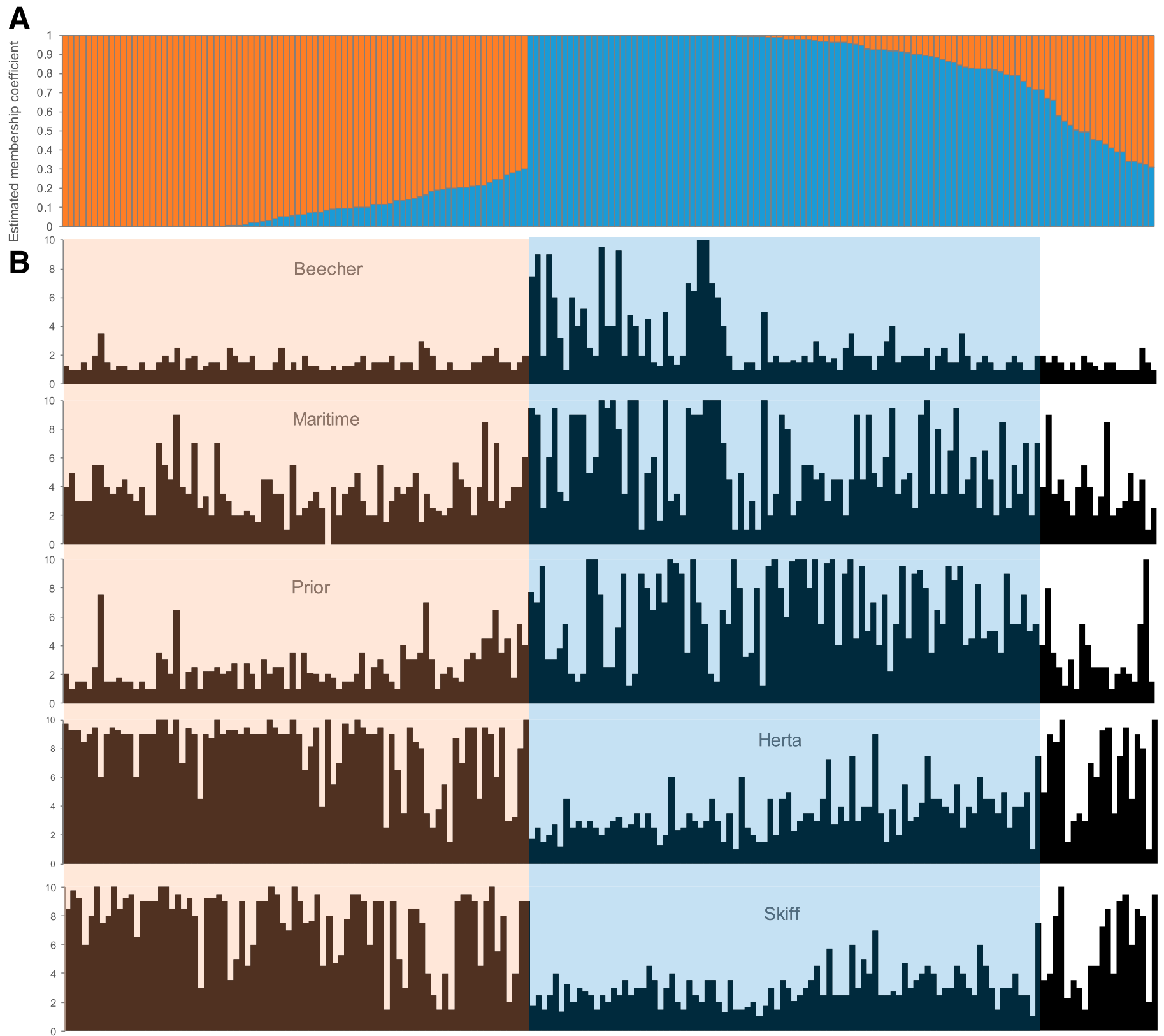

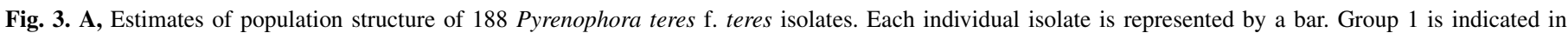

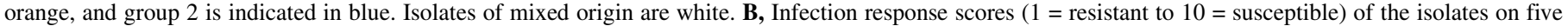
different genotypes: Beecher, Maritime, Prior, Herta, and Skiff. Individuals have been ordered according to the order on the population structure bar plot. 
Herta phenotypes in the GWAS analysis (Table 1). A major QTL was also identified on chromosome 3 on Beecher in the NB029/ NB085 population, explaining $36 \%$ of the phenotypic variation $(\mathrm{LOD}=12.0)$ (Table 2). This QTL was in a different location from the one identified on Skiff, but it was in the same location as the GWAS QTL3 identified with the Beecher, Maritime, and Kombarvirulent phenotype. Three minor QTL were identified in the NB029/HRS09122 population, with two located on chromosome 5 and one located on chromosome 9 (Table 2). The chromosome 5 QTL were in a similar location to QTL10 and QTL11 identified in the GWAS analysis; however, they were identified with different virulence phenotypes: against Fleet and Yerong for QTL10 and Harbin and Prior for QTL11. Minor QTL identified in the NB029/ NB085 population were located on chromosomes 7 and 8 (Table 2).

Analysis of QTL regions to identify candidate effector genes. The association mapping QTL regions in W1-1 were investigated for predicted effector genes, secondary metabolite biosynthetic gene clusters, Guanine, Cytosine (GC) content, and presence/absence in a number of $P$. teres $\mathrm{f}$. teres isolates with different barley cultivar virulence to identify candidate genes. Although most QTL were in GC-equilibrated regions, chromosome 5 QTL10 and QTL11, chromosome 6 QTL13, and chromosome 9
QTL14 were clearly found in the Adenine, Thymine (AT)-rich regions of the genome with sparse gene content (Supplementary Fig. S7).

The gene content in the 14 QTL regions identified from the association mapping was then examined against the reference isolate W1-1, and a total of 85 genes were present (Supplementary Table S2). Of these, 20 were predicted effectors according to EffectorP (Sperschneider et al. 2016, 2018), with a score $>0.5$ (Table 1). A single predicted effector (Ptt_W11.g06727) was also identified as a known secreted protein associated with virulence, G7 (XP_003297558.1) (Ismail and Able 2017), within QTL11 on chromosome 5 (Table 3 ). Of the 20 predicted effectors, 12 were hypothetical proteins and lacked any known protein domains. Only four predicted effector genes had known protein domains annotated by the protein family database, Pfam (Finn et al. 2016). These domains were related to an unknown function DUF1168 (PF06658; Ptt_W11.g00010), a membrane translocon-associated protein (PF03896; Ptt_W11.g03157), an orosomucoid-like (ORMDL) family protein believed to be involved in protein folding in the endoplasmic reticulum (PF04061; Ptt_W11.g06660), and a glycosyl transferase, family 28 C-terminal domain (PF04101; Ptt_ W11.g06663) (Supplementary Table S2).

For the W1-1 genome, a total of 57 biosynthetic gene clusters were identified, and although many biosynthetic gene clusters
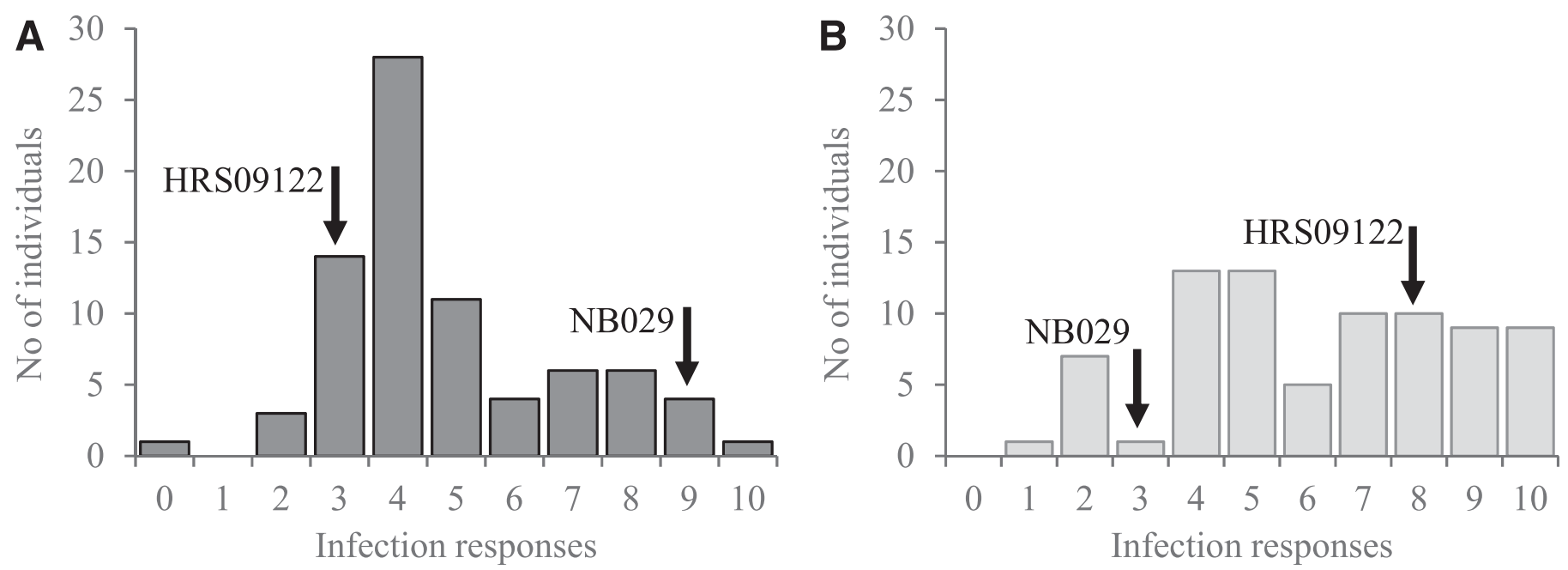

Fig. 4. Infection responses of 78 individuals of the NB029/HRS09122 population on barley genotypes A, Beecher and B, Skiff. Infection responses of the parental isolates NB029 and HRS09122 are indicated.
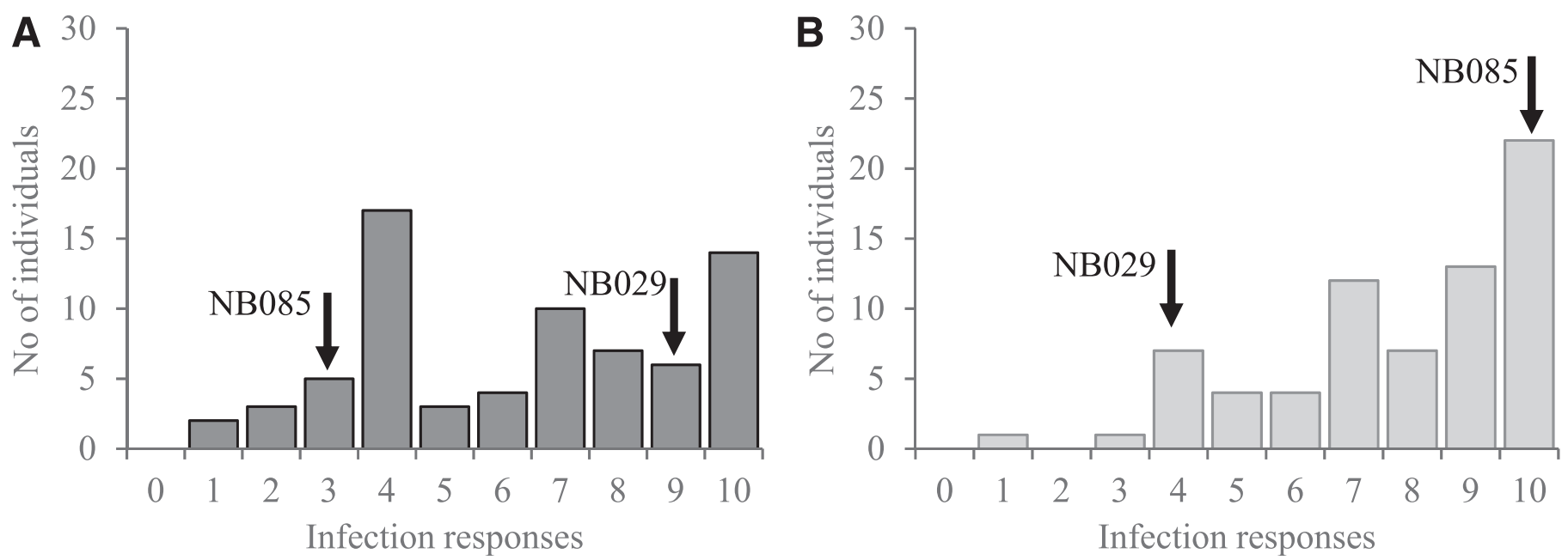

Fig. 5. Infection responses of 72 individuals of the NB029/NB085 population on barley genotypes A, Beecher and B, Prior. Infection responses of the parental isolates NB029 and NB085 are indicated. 
flanked the QTL regions, only 2 overlapped QTL2 and QTL4 by a few genes on chromosome 3 . These two gene clusters were represented by a single hybrid T1PKS-NRPS (polyketide synthasenonribosomal peptide synthetase) cluster and an nonribosomal peptide synthetase (NRPS), respectively (Supplementary Fig. S7).

To identify QTL regions containing potential effector genes with virulence specificity to particular barley cultivars, the genomes of six isolates were aligned and summarized against the QTL regions in W1-1 (Supplementary Fig. S7 and
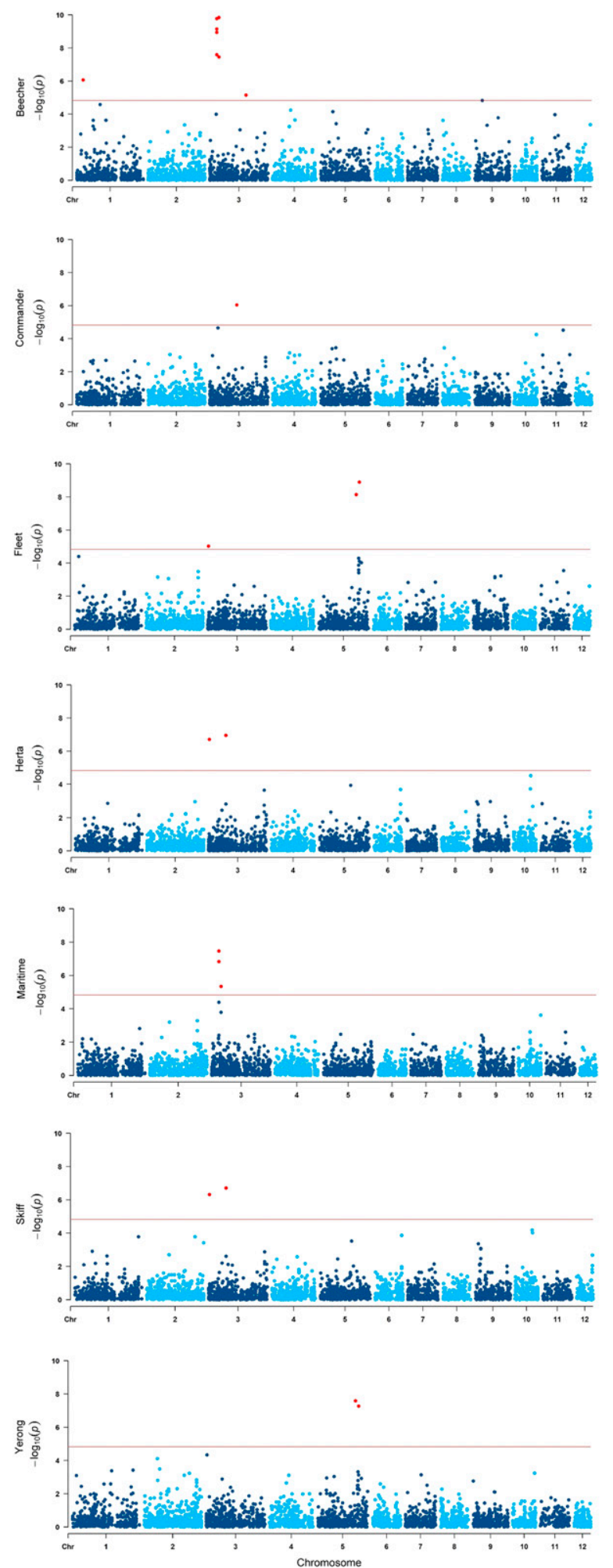

Supplementary Table S5), a virulent isolate on barley cultivar Beecher located close to NB029 in the model-based structuring analysis (Supplementary Table S4). A single QTL region (QTL3) on chromosome 3 was conserved in the two Beecher-infecting isolates (W1-1 and NB029) and lacked sequence conservation for the remaining isolates, which have virulence to different barley cultivars. This region contained a single small predicted effector protein (55 amino acids) identified in W1-1 (Ptt_ W11.g03125) that had $100 \%$ sequence identity in NB029 and no
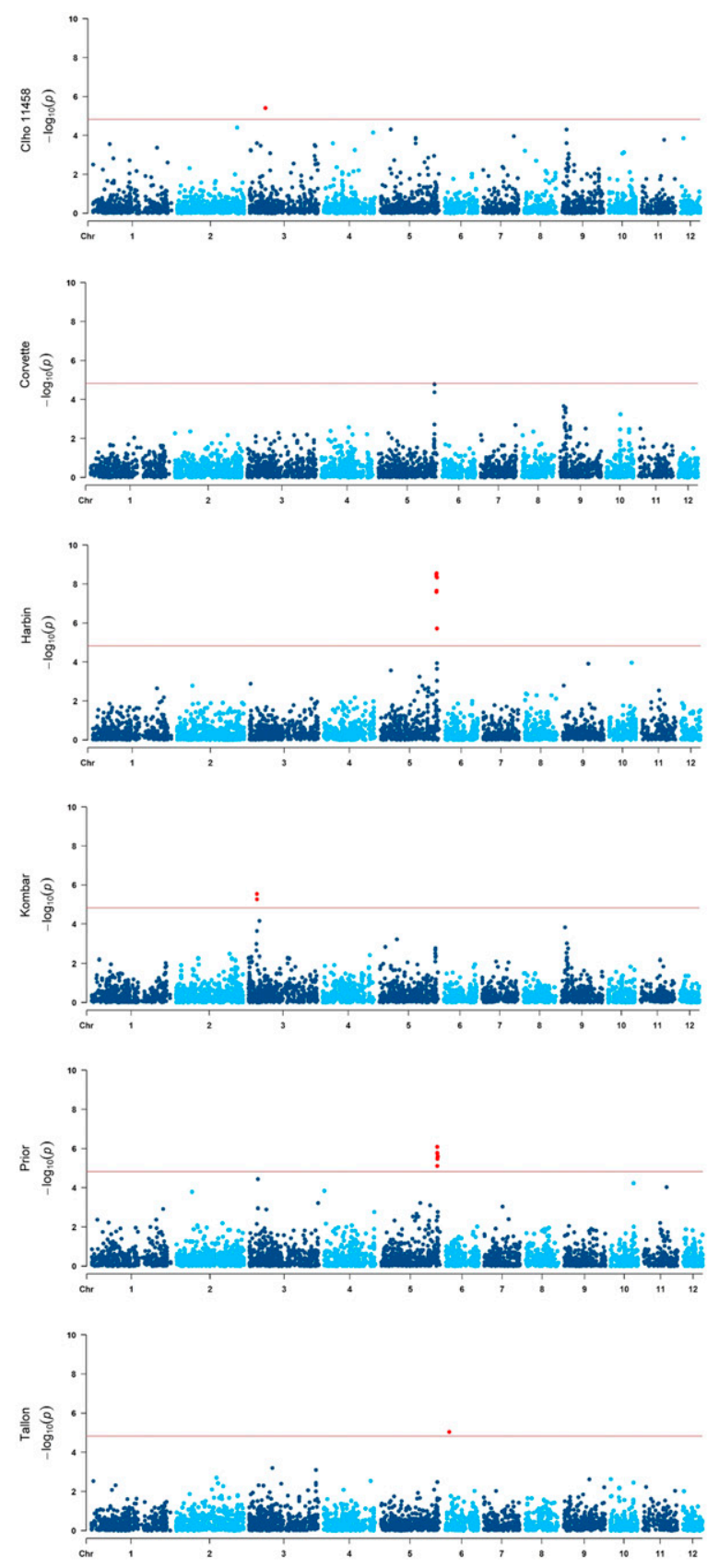

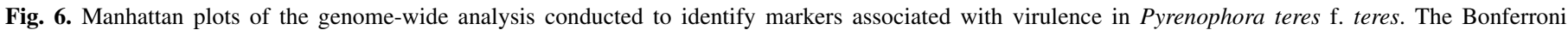
significance threshold is indicated by the solid red lines. 
homology in the remaining genomes (NB73, HRS9122, HRS9139, and NB085).

\section{DISCUSSION}

Barley is grown across a distance of $>3,000 \mathrm{~km}$ in Australia. To gain an overview of the composition of virulence genes present in the $P$. teres $\mathrm{f}$. teres population, a combination of genetic structuring, association mapping, and biparental mapping was undertaken. Model-based genetic structuring analysis of 188 $P$. teres f. teres isolates indicated that the most likely number of clusters is two. This is the same number of $K$ groups as identified by Ellwood et al. (2019) using isolates from Western Australia only. An association between the clusters and some of the phenotypic assessments of the isolates was observed with most of the isolates virulent on Beecher, Maritime, and Prior clustering in one group and those showing greater infection rates on Herta and Skiff clustering in group 2. By producing a hierarchical cluster dendrogram of 31 barley genotypes using phenotypic data from 123 P. teres f. teres isolates Fowler et al. (2017) identified seven groups of barley genotypes that responded similarly called line groups (LGs). Interestingly, Herta and Skiff were also closely clustered in the same LG (LG2), whereas Beecher, Maritime, and Prior were clustered in LG6 and LG7, which showed similar infection responses. Although some previous studies have investigated possible correlations between distinct populations and virulence spectra, none found a clear association between phenotypes and molecular clusters (Lehmensiek et al. 2010; Liu et al. 2012). Liu et al. (2012) identified 40 genotypes in a North Dakota $P$. teres f. teres population using microsatellite markers and suggested that this was similar to the number of identified pathotypes (49) based on a differential set of 22 barley lines. They found that isolates with a high level of genetic similarity also had similar virulence patterns. Liu et al. (2012) explained that isolates that were genotypically similar but had phenotypic differences may result from single genetic mutations that lead to changes in virulence without affecting the neighboring microsatellite markers or that the markers were not closely linked to genes controlling virulence. Our study indicated an association between some virulence rates and genotypes, suggesting that DArTseq markers may be more useful in genetic diversity studies.

Association mapping in this study provided an approximate LD half-decay value of $20 \mathrm{~kb}$ for Australian P. teres f.teres isolates. This value seems to vary in ascomycetes, with a rapid decay of $<0.1$ $\mathrm{kb}$ in some species (such as Schizophyllum commune) and up to 162 $\mathrm{kb}$ in Candida albicans (Nieuwenhuis and James 2016). The relatively low $\mathrm{LD}$ value of the Australian P. teres f. teres isolates suggests frequent sexual reproduction (Nieuwenhuis and James 2016).

Marker associations using GWAS analysis were observed for 13 of the 20 barley genotypes. Genotypes without any marker associations were mainly those with a poor distribution of infection responses either being mostly resistant (CIho 5791 and Vlamingh) (Supplementary Fig. S2) or mostly susceptible (Gilbert, Harrington, and Hindmarsh). However, GWAS analysis across 13 genotypes allowed 14 different QTL regions to be identified, and these were mainly located on chromosomes 3 and 5 . The number of virulence QTL in P. teres f. teres corresponds to the complexity of the host resistance genetics (Liu et al. 2011; Richards et al. 2017) and an expanded genome with evidence of relatively rapid transposondriven changes (Dong et al. 2015; Syme et al. 2018).

Interestingly, isolates virulent on Herta and Skiff, which clustered within one group of the STRUCTURE analysis, also showed association with the same markers on chromosome 3 in the GWAS analysis. Similarly, isolates virulent on Beecher and Maritime, which were clustered within the other group identified by STRUCTURE analysis, also had QTL in common on chromosome 3. It is known that some isolates with virulence to Beecher also show virulence to Maritime (Fowler et al. 2017), including the isolate NB029 used in our biparental mapping populations. This suggests that the QTL identified on chromosome 3 are the ones responsible for both the Beecher and Maritime virulence. In Australia, 97\% of the isolates of the P. teres f.teres population are virulent on Maritime, Prior, Skiff, or Tallon (Fowler et al. 2017). We identified different genomic regions significantly associated with all of these virulence rates.

We collected as many ejected ascospores as we could from the two $P$. teres $\mathrm{f}$. teres populations used in this study as opposed to collecting single ascospores from groups of ascospores, which avoids clones originating from the same ascus (Shjerve et al. 2014), because after meiosis, four pairs of identical ascospores are present in an ascus (Fincham 1971). DArTseq markers were used to identify genetically identical individuals. Marker data indicated that 29 of 107 (27\%) ascospores sampled for the NB029/ HRS09122 population and 17 of 89 (19\%) ascospores sampled for the NB029/NB085 population were genetically identical. Thus, collecting all of the ascospores resulted in a higher number of useful individuals per population.

Isolate NB029, which was used as one of the parents in both populations, is virulent on barley variety Beecher, whereas the other parental isolates (HRS09122 and NB085) are virulent on Skiff and Prior, respectively. Transgressive segregation for both populations was observed when phenotyping individual ascospores across the genotypes on which the parental isolates were virulent. This suggested the involvement of more than one gene and that progeny possessed different gene combinations to the parental isolates. Similar to our results, Weiland et al. (1999) found that many of the progeny produce infection responses different from those of the parents in a cross between $P$. teres $\mathrm{f}$. teres isolate $0-1$ possessing high virulence on barley cultivar Harbin and $P$. teres f. teres $15 \mathrm{~A}$ possessing low virulence on Harbin. Transgressive segregation was also observed in a cross between isolate BB25 from Denmark and isolate FGOH04Ptt-21 from North Dakota, U.S.A., indicating that these isolates had different sets of virulence and/or avirulence genes (Koladia et al. 2017).

Genetic maps constructed of the two P. teres f. teres populations consisted of 12 chromosomes, which is in agreement with the findings of Syme et al. (2018). Syme et al. (2018) constructed comprehensive genome assemblies of $P$. teres $\mathrm{f}$. teres. The total map distances for the two populations used in our study were 1,548 and $1,998 \mathrm{cM}$. These map distances are similar to the total map size of $1,906 \mathrm{cM}$ reported by Koladia et al. (2017) for the P. teres f. teres population BB25/FGOHo4Ptt-21. Their largest linkage group was $231 \mathrm{cM}$ in length compared with 290.85 and $227.39 \mathrm{cM}$ in this study.

Two major QTL were identified on chromosome 3 in both populations NB029/HRS09122 and NB029/NB085, albeit in different locations. The QTL associated with phenotyping on Skiff in the NB029/HRS09122 population was contributed by HRS09122, and NB029 contributed the virulence allele on Beecher in the NB029/NB085 population. The Beecher QTL was also associated with Beecher and Maritime virulence using GWAS. This QTL was in a similar location to a virulence locus VK1 reported by Shjerve et al. (2014). They are separate, however, with a distance of approximately $58 \mathrm{~kb}$ between their flanking markers (F. Timothy, U.S. Department of Agriculture-Agriculture Research Service (USDA-ARS), personal communication). In a 2017 study, P. teres f. tere QTL explaining up to $56 \%$ of the phenotypic variation were identified using cultivar Beecher on linkage groups 1.1 and 2.1 (chromosomes were numbered in that study to correspond with $P$. tritici-repentis chromosomes numbers), with the virulence allele contributed by a North Dakota, U.S.A. isolate FGOH04Ptt-21 (Koladia et al. 2017). Neither of these QTL seem to be in the same region as the Beecher QTL identified in our study, suggesting that QTL governing the same cultivar virulence may not be conserved between geographically distant isolates. 
AT-rich regions in filamentous fungal pathogens are considered to be important in generating pathogenesis effectors (Dong et al. 2015; Raffaele and Kamoun 2012; Wyatt et al. 2020). Sequence analysis of the QTL regions indicated that the majority of chromosome 5 and the chromosome 9 QTL were in or flanked by ATrich regions, but the chromosome 3 QTL were in GC-equilibrated genomic regions. Thus, $P$. teres $\mathrm{f}$. teres presents a more complex scenario in which such regions may be a result of transposition events because they typically include miniature inverted-repeat transposable elements (MITEs) and long terminal repeats (LTRs) (unpublished data). Chromosome 3 QTL also appeared colocated with a region of biosynthetic gene cluster expansion (Syme et al. 2018) compared with $P$. teres f. maculata and P. tritici-repentis, although these only partly overlapped the QTL. Closer examination

TABLE 1. Genome-wide association mapping results indicating markers significantly associated with virulence in Pyrenophora teres f. teres

\begin{tabular}{|c|c|c|c|c|c|c|c|}
\hline QTL ID $^{\mathrm{a}}$ & Trait & Marker & Chromosome $^{\mathrm{b}}$ & Position $^{\mathrm{b}}$ (bp) & LOD score ${ }^{c}$ & $\mathrm{PVE}^{\mathrm{d}}$ & Biparental mapping \\
\hline 1 & Beecher & 28947393 & 1 & 679123 & 6.07 & 14.58 & \\
\hline 2 & Fleet & 41806492|F|0-7:A>G-7:A>G & 3 & 102867 & 5.02 & 18.93 & Skiff, NB029/HRS09122 \\
\hline 2 & Herta & 28949576 & 3 & 114611 & 6.70 & 16.33 & Skiff, NB029/HRS09122 \\
\hline 2 & Skiff & 28949576 & 3 & 114611 & 6.32 & 15.15 & Skiff, NB029/HRS09122 \\
\hline 3 & Beecher & 28946135 & 3 & 788584 & 8.94 & 21.62 & Beecher, NB029/NB085 \\
\hline 3 & Beecher & 41805542 & 3 & 795925 & 9.15 & 21.92 & Beecher, NB029/NB085 \\
\hline 3 & Kombar & 41805542 & 3 & 795925 & 5.26 & 12.07 & Beecher, NB029/NB085 \\
\hline 3 & Maritime & 41805542 & 3 & 795925 & 6.83 & 16.38 & Beecher, NB029/NB085 \\
\hline 3 & Beecher & 28945535 & 3 & 796216 & 7.60 & 17.50 & Beecher, NB029/NB085 \\
\hline 3 & Beecher & 100130307 & 3 & 796281 & 9.77 & 23.58 & Beecher, NB029/NB085 \\
\hline 3 & Kombar & 100130307 & 3 & 796281 & 5.54 & 12.97 & Beecher, NB029/NB085 \\
\hline 3 & Maritime & 100130307 & 3 & 796281 & 7.47 & 18.65 & Beecher, NB029/NB085 \\
\hline 4 & Beecher & 36352701 & 3 & 1028769 & 7.46 & 17.48 & \\
\hline 4 & Maritime & 36352701 & 3 & 1028769 & 5.34 & 12.71 & \\
\hline 5 & CIho 11458 & 100133310 & 3 & 1480380 & 5.41 & 12.46 & \\
\hline 6 & Herta & 28945761 & 3 & 1905727 & 6.95 & 16.93 & \\
\hline 6 & Skiff & 28945761 & 3 & 1905727 & 6.71 & 16.12 & \\
\hline 7 & Beecher & $28949829|\mathrm{~F}| 0-28: \mathrm{C}>\mathrm{T}-28: \mathrm{C}>\mathrm{T}$ & 3 & 3985143 & 5.15 & 11.03 & \\
\hline 8 & Commander & 28945998 & 3 & 5556417 & 5.05 & 12.69 & \\
\hline 9 & Fleet & 28948035 & 5 & 4110850 & 8.14 & 21.47 & \\
\hline 9 & Yerong & 28948035 & 5 & 4110850 & 7.59 & 18.72 & \\
\hline 10 & Fleet & 36347132 & 5 & 4456299 & 8.89 & 22.98 & Skiff, NB029/HRS09122 \\
\hline 10 & Yerong & 36347132 & 5 & 4456299 & 7.27 & 17.55 & Skiff, NB029/HRS09122 \\
\hline 11 & Harbin & $28950148|\mathrm{~F}| 0-5: \mathrm{A}>\mathrm{C}-5: \mathrm{A}>\mathrm{C}$ & 5 & 5195933 & 7.59 & 21.31 & Beecher, NB029/HRS09122 \\
\hline 11 & Prior & $28950148|\mathrm{~F}| 0-5: \mathrm{A}>\mathrm{C}-5: \mathrm{A}>\mathrm{C}$ & 5 & 5195933 & 5.11 & 13.50 & Beecher, NB029/HRS09122 \\
\hline 11 & Harbin & 36347644 & 5 & 5196299 & 8.39 & 21.10 & Beecher, NB029/HRS09122 \\
\hline 11 & Prior & 36347644 & 5 & 5196299 & 6.08 & 13.98 & Beecher, NB029/HRS09122 \\
\hline 11 & Harbin & 28945265 & 5 & 5196364 & 8.51 & 21.51 & Beecher, NB029/HRS09122 \\
\hline 11 & Prior & 28945265 & 5 & 5196364 & 5.78 & 13.10 & Beecher, NB029/HRS09122 \\
\hline 11 & Harbin & 28949624 & 5 & 5205990 & 8.55 & 21.66 & Beecher, NB029/HRS09122 \\
\hline 11 & Prior & 28949624 & 5 & 5205990 & 5.74 & 13.15 & Beecher, NB029/HRS09122 \\
\hline 11 & Harbin & 36350488 & 5 & 5209123 & 7.66 & 20.65 & Beecher, NB029/HRS09122 \\
\hline 11 & Prior & 36350488 & 5 & 5209123 & 5.48 & 12.72 & Beecher, NB029/HRS09122 \\
\hline 12 & Corvette & $36352140|\mathrm{~F}| 0-22: \mathrm{T}>\mathrm{C}-22: \mathrm{T}>\mathrm{C}$ & 5 & 5243799 & 4.79 & 14.19 & \\
\hline 12 & Harbin & 36352141 & 5 & 5243799 & 8.34 & 21.61 & \\
\hline 12 & Harbin & $36352140|\mathrm{~F}| 0-22: \mathrm{T}>\mathrm{C}-22: \mathrm{T}>\mathrm{C}$ & 5 & 5243799 & 5.71 & 19.00 & \\
\hline 12 & Prior & 36352141 & 5 & 5243799 & 5.58 & 12.95 & \\
\hline 13 & Tallon & 100139818 & 6 & 410017 & 5.04 & 10.90 & \\
\hline 14 & Beecher & 28949038 & 9 & 839959 & 4.82 & 10.19 & \\
\hline
\end{tabular}

a ID, identification; QTL, quantitative trait locus.

b Chromosome on which the marker is located and position according to the W1-1 reference genome (Syme et al. 2018).

c Logarithm of the odds (LOD).

d Percentage of phenotypic variance explained (PVE).

e Indicates QTL that were also identified in biparental mapping populations, showing trait associated with virulence QTL and population.

TABLE 2. Summary of quantitative trait loci identified in Pyrenophora teres $\mathrm{f}$. teres populations NB029/HRS09122 and NB029/NB085

\begin{tabular}{|c|c|c|c|c|c|c|}
\hline Chromosome number & Position of peak of QTL ${ }^{a}(\mathrm{cM})$ & Genotype $^{\mathrm{b}}$ & LOD score ${ }^{c}$ & $R^{2 \mathrm{~d}}$ & Parent contributing the QTL & Position on W1-1 reference genome $\mathrm{e}^{\mathrm{e}}$ \\
\hline \multicolumn{7}{|l|}{ NB029/HRS09122 } \\
\hline 3 & 258 & Skiff & 6.6 & 24 & HRS09122 & 114611 \\
\hline 5 & 11 & Beecher & 4.0 & 15 & NB029 & $5183980-5208563$ \\
\hline 5 & 39 & Skiff & 4.8 & 19 & HRS09122 & $3980200-4457075$ \\
\hline 9 & 39 & Beecher & 3.0 & 11 & NB029 & $1073073-1122817$ \\
\hline \multicolumn{7}{|l|}{ NB029/NB085 } \\
\hline 3 & 21 & Beecher & 12.0 & 36 & NB029 & $796216-970812$ \\
\hline 7 & 49 & Beecher & 3.9 & 11 & NB085 & 2166986-2928737 \\
\hline 7 & 49 & Prior & 3.6 & 18 & NB085 & 2166986-2928737 \\
\hline 8 & 22 & Beecher & 3.0 & 7 & NB029 & 1883966-1972858 \\
\hline
\end{tabular}

a QTL, quantitative trait locus.

b Genotype on which QTL was identified.

c Logarithm of the odds (LOD).

d Percentage of phenotypic variation explained.

e Position of QTL on W1-1 reference genome (Syme et al. 2018). 
TABLE 3. Pyrenophora teres f. teres isolate W1-1 summary of predicted effector genes associated with quantitative trait loci (QTL) genomic regions

\begin{tabular}{|c|c|c|c|c|c|c|}
\hline W1-1 chromosome & QTL identification & QTL start & QTL end & Number of predicted effectors & Biosynthetic cluster type & Secreted proteins \\
\hline 1 & QTL1 & 659123 & 699123 & 3 & & \\
\hline 3 & QTL2 & 94611 & 134611 & 2 & & \\
\hline 3 & QTL3 & 768584 & 816281 & 1 & & \\
\hline 3 & QTL4 & 1008769 & 1048769 & 2 & NRPS ${ }^{a}$ & \\
\hline 3 & QTL5 & 1460380 & 1500380 & 1 & NRPS & \\
\hline 3 & QTL6 & 1885727 & 1925727 & 2 & & \\
\hline 3 & QTL7 & 3965143 & 4005143 & 2 & & \\
\hline 3 & QTL8 & 5536417 & 5576417 & 2 & & \\
\hline 5 & QTL9 & 4090850 & 4130850 & 3 & & \\
\hline 5 & QTL10 & 4436299 & 4476299 & 0 & & \\
\hline 5 & QTL11 & 5175933 & 5229123 & 2 & & $\mathrm{G} 7^{\mathrm{b}}$ \\
\hline 5 & QTL12 & 5223799 & 5263799 & 0 & & \\
\hline 6 & QTL13 & 390017 & 430017 & 0 & & \\
\hline 9 & QTL14 & 819959 & 859959 & 0 & & \\
\hline
\end{tabular}

a Nonribosomal peptide synthetase (NRPS).

b Secreted proteins identified by Ismail and Able (2016). Virulent RNA expression for P. teres f. teres proteins (Ismail and Able 2017).

of the P. teres f. teres isolate W1-1 QTL regions and the genomes of other P. teres f. teres isolates from Syme et al. (2018) identified a genomic region that was specific to Beecher virulent isolates W1-1 and NB029 on chromosome 3 (QTL3). This region may, therefore, contain possible candidates for Beecher-specific virulence, one candidate for which is a predicted effector gene.

In conclusion, this is the first GWAS undertaken to identify loci associated with virulence in $P$. teres. The confirmation of some of these loci by biparental QTL mapping demonstrates the effective use of this approach with this pathogen. The identification of predicted pathogenicity effector genes in the QTL regions and a potential role of NRPS biosynthetic clusters flanking QTL on chromosome 3 both require further characterization. The number of genomic regions found to be associated with different virulence among Australian pathotypes demonstrates the need for phenotyping and breeding strategies to introgress multiple resistance genes into future barley cultivars.

\section{ACKNOWLEDGMENTS}

We thank Kiruba Arun-Chinnappa and Janet Barsby for their technical support. We also thank the Australian Government National Collaborative Research Infrastructure Strategy for providing access to Pawsey Supercomputing under a National Computational Merit Allocation Scheme and Nectar Research and Pawsey Nimbus Cloud resources.

\section{LITERATURE CITED}

Beattie, A. D., Scoles, G. J., and Rossnagel, B. G. 2007. Identification of molecular markers linked to a Pyrenophora teres avirulence gene. Phytopathology 97:842-849.

Blin, K., Shaw, S., Steinke, K., Villebro, R., Ziemert, N., Lee, S. Y., Medema, M. H., and Weber, T. 2019. antiSMASH 5.0: Updates to the secondary metabolite genome mining pipeline. Nucleic Acids Res. 47:W81-W87.

Bradbury, P. J., Zhang, Z., Kroon, D. E., Casstevens, T. M., Ramdoss, Y., and Buckler, E. S. 2007. TASSEL: Software for association mapping of complex traits in diverse samples. Bioinformatics 23:2633-2635.

Broberg, M., Dubey, M., Sun, M. H., Ihrmark, K., Schroers, H. J., Li, S. D., Jensen, D. F., Durling, M. B., and Karlsson, M. 2018. Out in the cold: Identification of genomic regions associated with cold tolerance in the biocontrol fungus Clonostachys rosea through genome-wide association mapping. Front. Microbiol. 9:2844.

Campbell, G. F., Crous, P. W., and Lucas, J. A. 1999. Pyrenophora teres f. maculata, the cause of Pyrenophora leaf spot of barley in South Africa. Mycol. Res. 103:257-267.

Castiblanco, V., Marulanda, J. J., Wurschum, T., and Miedaner, T. 2017. Candidate gene based association mapping in Fusarium culmorum for field quantitative pathogenicity and mycotoxin production in wheat. BMC Genet. $18: 49$.

Courtois, B., Audebert, A., Dardou, A., Roques, S., Ghneim-Herrera, T., Droc, G., Frouin, J., Rouan, L., Goze, E., Kilian, A., Ahmadi, N., and Dingkuhn, M. 2013. Genome-wide association mapping of root traits in a Japonica rice panel. PLoS One 8:e78037.
Cruz, V. M. V., Kilian, A., and Dierig, D. A. 2013. Development of DArT marker platforms and genetic diversity assessment of the US Collection of the new oilseed crop Lesquerella and related species. PLoS One 8:e64062.

Delcher, A. L., Salzberg, S. L., and Phillippy, A. M. 2003. Using MUMmer to identify similar regions in large sequence sets. Curr. Protoc. Bioinform. 10: 10.3

Earl, D. A., and Vonholdt, B. M. 2012. STRUCTURE HARVESTER: A website and program for visualizing STRUCTURE output and implementing the Evanno method. Conserv. Gen. Resour. 4:359-361.

Dong, S. M., Raffaele, S., and Kamoun, S. 2015. The two-speed genomes of filamentous pathogens: Waltz with plants. Curr. Opin. Genet. Dev. 35: 57-65.

Ellwood, S. R., Piscetek, V., Mair, W. J., Lawrence, J. A., Lopez-Ruiz, F. J., and Rawlinson, C. 2019. Genetic variation of Pyrenophora teres f. teres isolates in Western Australia and emergence of a Cyp51A fungicide resistance mutation. Plant Pathol. 68:135-142.

Ellwood, S. R., Syme, R. A., Moffat, C. S., and Oliver, R. P. 2012. Evolution of three Pyrenophora cereal pathogens: Recent divergence, speciation and evolution of non-coding DNA. Fungal Genet. Biol. 49:825-829.

Elshire, R. J., Glaubitz, J. C., Sun, Q., Poland, J. A., Kawamoto, K., Buckler, E. S., and Mitchell, S. E. 2011. A robust, simple genotyping-by-sequencing (GBS) approach for high diversity species. PLoS One 6.

Evanno, G., Regnaut, S., and Goudet, J. 2005. Detecting the number of clusters of individuals using the software STRUCTURE: A simulation study. Mol. Ecol. 14:2611-2620.

Falush, D., Stephens, M., and Pritchard, J. K. 2007. Inference of population structure using multilocus genotype data: Dominant and null alleles. Mol. Ecol. Notes 7:574-578.

Fincham, J. R. S. 1971. Using Fungi to Study Genetic Recombination. Oxford University Press, Oxford, Great Britain.

Finn, R. D., Coggill, P., Eberhardt, R. Y., Eddy, S. R., Mistry, J., Mitchell, A. L., Potter, S. C., Punta, M., Qureshi, M., Sangrador-Vegas, A., Salazar, G. A., Tate, J., and Bateman, A. 2016. The Pfam protein families database: Towards a more sustainable future. Nucleic Acids Res. D279-D285.

Fowler, R. A., Platz, G. J., Bell, K. L., Fletcher, S. E. H., Franckowiak, J. D., and Hickey, L. T. 2017. Pathogenic variation of Pyrenophora teres f. teres in Australia. Australas. Plant Pathol. 46:115-128.

Gao, Y. Y., Liu, Z. H., Faris, J. D., Richards, J., Brueggeman, R. S., Li, X. H., Oliver, R. P., McDonald, B. A., and Friesen, T. L. 2016. Validation of genome-wide association studies as a tool to identify virulence factors in Parastagonospora nodorum. Phytopathology 106:1177-1185.

Hartmann, F. E., Sanchez-Vallet, A., McDonald, B. A., and Croll, D. 2017. A fungal wheat pathogen evolved host specialization by extensive chromosomal rearrangements. ISME J. 11:1189-1204.

Hebert, T. T. 1971. The perfect stage of Pyricularia grisea. Phytopathology 61:83-87.

Ismail, I. A., and Able, A. J. 2016. Secretome analysis of virulent Pyrenophora teres f. teres isolates. Proteomics 16:2625-2636.

Ismail, I. A., and Able, A. J. 2017. Gene expression profiling of virulenceassociated proteins in planta during net blotch disease of barley. Physiol. Mol. Plant Pathol. 98:69-79.

Jakobsson, M., and Rosenberg, N. A. 2007. CLUMPP: A cluster matching and permutation program for dealing with label switching and multimodality in analysis of population structure. Bioinformatics 23:1801-1806.

Jalli, M. 2011. Sexual reproduction and soil tillage effects on virulence of Pyrenophora teres in Finland. Ann. Appl. Biol. 158:95-105.

Jordan, V. W. L. 1981. Aetiology of barley net blotch caused by Pyrenophora teres and some effects on yield. Plant Pathol. 30:77-87. 
Kilian, A., Wenzl, P., Huttner, E., Carling, J., Xia, L., Blois, H., Caig, V., Heller-Uszynska, K., Jaccoud, D., Hopper, C., Aschenbrenner-Kilian, M., Evers, M., Peng, K., Cayla, C., Hok, P., and Uszynski, G. 2012. Diversity arrays technology: A generic genome profiling technology on open platforms. Methods Mol. Biol. 888:67-89.

Koladia, V. M., Richards, J. K., Wyatt, N. A., Faris, J. D., Brueggeman, R. S., and Friesen, T. L. 2017. Genetic analysis of virulence in the Pyrenophora teres f. teres population BB25 $\times$ FGOH04Ptt-21. Fungal Genet. Biol. 107:12-19.

Korinsak, S., Tangphatsornruang, S., Pootakham, W., Wanchana, S., Plabpla, A., Jantasuriyarat, C., Patarapuwadol, S., Vanavichit, A., and Toojinda, T. 2019. Genome-wide association mapping of virulence gene in rice blast fungus Magnaporthe oryzae using a genotyping by sequencing approach. Genomics 111:661-668.

Lai, Z. B., Faris, J. D., Weiland, J. J., Steffenson, B. J., and Friesen, T. L. 2007. Genetic mapping of Pyrenophora teres f. teres genes conferring avirulence on barley. Fungal Genet. Biol. 44:323-329.

Lehmensiek, A., Bester-van der Merwe, A. E., Sutherland, M. W., Platz, G., Kriel, W. M., Potgieter, G. F., and Prins, R. 2010. Population structure of South African and Australian Pyrenophora teres isolates. Plant Pathol. 59: 504-515.

Lightfoot, D. J., and Able, A. J. 2010. Growth of Pyrenophora teres in planta during barley net blotch disease. Austral. Plant Pathol. 39:499-507.

Liu, Z. H., Ellwood, S. R., Oliver, R. P., and Friesen, T. L. 2011. Pyrenophora teres: Profile of an increasingly damaging barley pathogen. Mol. Plant Pathol. 12:1-19.

Liu, Z. H., Zhong, S., Stasko, A. K., Edwards, M. C., and Friesen, T. L. 2012. Virulence profile and genetic structure of a North Dakota population of Pyrenophora teres f. teres, the causal agent of net form net blotch of barley. Phytopathology 102:539-546.

Manly, K. F., Cudmore, J. R. H., and Meer, J. M. 2001. Map Manager QTX, cross-platform software for genetic mapping. Mammalian Genome 12: 930-932.

McLean, M. S., Howlett, B. J., and Hollaway, G. J. 2009. Epidemiology and control of spot form of net blotch (Pyrenophora teres f. maculata) of barley: A review. Crop Pasture Sci. 60:303-315.

Nieuwenhuis, B. P. S., and James, T. Y. 2016. The frequency of sex in fungi. Philos. Trans. R. Soc. B Biol. Sci. 371:20150540.

Piening, L. J. 1961. The occurrence of Pyrenophora teres on barley straw in Alberta. Can. Plant Dis. 41:299-300.

Poudel, B., Ellwood, S. R., Testa, A. C., McLean, M., Sutherland, M. W., and Martin, A. 2017. Rare Pyrenophora teres hybridization events revealed by development of sequence-specific PCR markers. Phytopathology 107:878-884.

Poudel, B., McLean, M. S., Platz, G. J., McIlroy, J. A., Sutherland, M. W., and Martin, A. 2019a. Investigating hybridisation between the forms of Pyrenophora teres based on Australian barley field experiments and cultural collections. Eur. J. Plant Pathol. 153:465-473.

Poudel, B., Vaghefi, N., McLean, M., Platz, G., Sutherland, M., and Martin, A. 2019b. Genetic structure of a Pyrenophora teres f. teres population over time in an Australian barley field as revealed by Diversity Arrays Technology markers. Plant Pathol. 68:1331-1336.

Pritchard, J., and Wen, W. 2003. Documentation for STRUCTURE software: Version 2. https://web.stanford.edu/group/pritchardlab/software/readme_ structure2.pdf

Pritchard, J. K., Stephens, M., and Donnelly, P. 2000. Inference of population structure using multilocus genotype data. Genetics 155:945-959.

Quinlan, A. R. 2014. BEDTools: The Swiss-Army Tool for Genome Feature Analysis. Curr. Protoc. Bioinform. 47:11.12.1-34.

Raffaele, S., and Kamoun, S. 2012. Genome evolution in filamentous plant pathogens: Why bigger can be better. Nat. Rev. Microbiol. 10:417-430.

Raman, H., Raman, R., Kilian, A., Detering, F., Carling, J., Coombes, N., Diffey, S., Kadkol, G., Edwards, D., McCully, M., Ruperao, P., Parkin, I. A. P., Batley, J., Luckett, D. J., and Wratten, N. 2014. Genome-wide delineation of natural variation for pod shatter resistance in Brassica napus. PLoS One 9:e101673.
Rau, D., Attene, G., Brown, A. H. D., Nanni, L., Maier, F. J., Baftnas, V., Saba, E., Schafer, W., and Papa, R. 2007. Phylogeny and evolution of mating-type genes from Pyrenophora teres, the causal agent of barley "net blotch" disease. Curr. Genet. 51:377-392.

Richards, J. K., Friesen, T. L., and Brueggeman, R. S. 2017. Association mapping utilizing diverse barley lines reveals net form net blotch seedling resistance/susceptibility loci. Theor. Appl. Genet. 130:915-927.

Sharma, M., Nagavardhini, A., Thudi, M., Ghosh, R., Pande, S., and Varshney, R. K. 2014. Development of DArT markers and assessment of diversity in Fusarium oxysporum f. sp ciceris, wilt pathogen of chickpea (Cicer arietinum L.). BMC Genomics 15:454.

Shipton, W. A. 1966. Effect of net blotch infection of barley on grain yield in quality. Aust. J. Exp. Agric. Anim. Husb. 6:437-440.

Shjerve, R. A., Faris, J. D., Brueggeman, R. S., Yan, C., Zhu, Y., Koladia, V., and Friesen, T. L. 2014. Evaluation of a Pyrenophora teres f. teres mapping population reveals multiple independent interactions with a region of barley chromosome 6H. Fungal Genet. Biol. 70:104-112.

Smedegård-Petersen. 1971. Pyrenophora teres f. maculata f. nov. and Pyrenophora teres f. teres on barley in Denmark. Pages 124-144 in: Royal Veterinary and Agricultural University Yearbook, Copenhagen, Denmark.

Sperschneider, J., Dodds, P. N., Gardiner, D. M., Singh, K. B., and Taylor, J. M. 2018. Improved prediction of fungal effector proteins from secretomes with EffectorP 2.0. Mol. Plant Pathol. 19:2094-2110.

Sperschneider, J., Gardiner, D. M., Dodds, P. N., Tini, F., Covarelli, L., Singh, K. B., Manners, J. M., and Taylor, J. M. 2016. EffectorP: Predicting fungal effector proteins from secretomes using machine learning. New Phytol. 210:743-761.

Syme, R. A., Martin, A., Wyatt, N. A., Lawrence, J. A., Muria-Gonzalez, M. J., Friesen, T. L., and Ellwood, S. R. 2018. Transposable element genomic fissuring in Pyrenophora teres is associated with genome expansion and dynamics of host-pathogen genetic interactions. Front. Genet. 9:130.

Talas, F., Kalih, R., Miedaner, T., and McDonald, B. A. 2016. Genome-wide association study identifies novel candidate genes for aggressiveness, deoxynivalenol production, and azole sensitivity in natural field populations of Fusarium graminearum. Mol. Plant-Microbe Interact. 29:417-430.

Tekauz, A. 1985. A numerical scale to classify reactions of barley to Pyrenophora teres. Can. J. Plant Pathol. 7:181-183.

Thorvaldsdottir, H., Robinson, J. T., and Mesirov, J. P. 2013. Integrative genomics viewer (IGV): High-performance genomics data visualization and exploration. Brief. Bioinform. 14:178-192.

Van Os, H., Stam, P., Visser, R. G. F., and Van Eck, H. 2005. RECORD: A novel method for ordering loci on a genetic linkage map. Theor. Appl. Genet. 112:30-40.

Voorrips, R. E. 2002. MapChart: Software for the graphical presentation of linkage maps and QTLs. J. Hered. 93:77-78.

Wang, S., Basten, C. J., and Zeng, Z.-B. 2007. Windows QTL Cartographer 2.5. Department of Statistics, North Carolina State University, Raleigh, NC. http://statgen.ncsu.edu/qtlcart/WQTLCart.htm

Weiland, J. J., Steffenson, B. J., Cartwright, R. D., and Webster, R. K. 1999. Identification of molecular genetic markers in Pyrenophora teres $\mathrm{f}$. teres associated with low virulence on 'Harbin' barley. Phytopathology 89: 176-181.

Wittenberg, A. H. J., van der Lee, T. A. J., Ben M'Barek, S., Ware, S. B., Goodwin, S. B., Kilian, A., Visser, R. G. F., Kema, G. H. J., and Schouten, H. J. 2009. Meiosis drives extraordinary genome plasticity in the haploid fungal plant pathogen Mycosphaerella graminicola. PLoS One 4:e5863.

Wyatt, N. A., Richards, J., Brueggeman, R. S., and Friesen, T. L. 2020. A comparative genomic analysis of the barley pathogen Pyrenophora teres $\mathrm{f}$. teres identifies subtelomeric regions as drivers of virulence. Mol. PlantMicrobe Interact. 33:173-188.

Zadoks, J. C., Chang, T. T., and Konzak, C. F. 1974. A decimal code for the growth stages of cereals. Weed Res. 14:415-421. 